\title{
Qualidade de Sementes de FeiJão (Phaseolus vulgaris) APós aplicação do Carfentrazone-Ethyl em PrÉ-Colheita ${ }^{1}$
}

\author{
Seed Quality of Bean (Phaseolus vulgaris) After Application of Carfentrazone-Ethyl in \\ Pre-Harvest
}

SANTOS, J.B. ${ }^{2}$, FERREIRA, E.A. ${ }^{3}$, SANTOS, E.A. ${ }^{4}$, SILVA, A.A. ${ }^{5}$, SILVA, F.M. $^{6}$ e FERREIRA, L.R. ${ }^{5}$

\begin{abstract}
RESUMO - Objetivou-se neste trabalho avaliar os efeitos da dessecação de plantas de feijão (cultivar Talismã) com carfentrazone-ethyl sobre a qualidade das sementes. Realizou-se a dessecação das plantas utilizando cinco doses $\left(0,10,30,60\right.$ e $\left.120 \mathrm{~g} \mathrm{ha}^{-1}\right)$ de carfentrazone associadas a três épocas de aplicação: 25, 30 e 35 dias após o florescimento (DAF). Em intervalos de dois dias após cada aplicação, quantificou-se a evolução da perda de umidade das sementes. Oito dias após cada aplicação, realizou-se a colheita, sendo determinados o peso de 100 sementes e a proporção de sementes classificadas como "pequenas" (que passaram por peneira de crivo 14/64"), "médias" (retidas entre as peneiras de crivo 14/64" e $16 / 64$ ") e "maiores" (que ficaram retidas na peneira de crivo 16/64"). A viabilidade das sementes foi avaliada pelo teste de germinação (TG). A aplicação de carfentrazone-ethyl em doses superiores a $60 \mathrm{~g} \mathrm{ha}^{-1}$ aos $25 \mathrm{DAF}$ acelerou a perda de umidade das sementes, afetando, o tamanho e o peso de 100 sementes. Melhores resultados foram obtidos com aplicação do dessecante nas doses entre 10 e $30 \mathrm{~g} \mathrm{ha}^{-1}$, aos $30 \mathrm{DAF}$, proporcionando melhor rendimento e qualidade das sementes, sem efeito negativo sobre a germinação.
\end{abstract}

Palavras-chave: dessecação química, herbicida, tamanho de sementes.

\begin{abstract}
This study aimed to evaluate the effects of bean desiccation (Talismã cultivar) with carfentrazone-ethyl on seed quality. Desiccation was performed by applying 5 rates $(0,10,30,60$ and $120 \mathrm{~g} \mathrm{ha}^{-1}$ ) of carfentrazone-ethyl associated to three application times, 25, 30 and 35 days after flowering (DAF). Humidity loss was quantified two days after each application. Harvest was performed eight days after each application, followed by determination of the weight of 100 seeds, and the proportion of seeds was classified as "small" (passed through sieve 14/64"), "medium" (retained in sieves 14/64" and 16/64") and "larger" (retained in sieves 16/64") and the germination

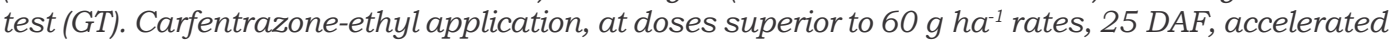
seed humidity loss, affecting the size and weight of 100 seeds. Desiccant application between 10 and $30 \mathrm{~g} \mathrm{ha}^{-1}$ rates, $30 \mathrm{DAF}$, provided better results, larger yield and seed quality without a negative effect on germination.
\end{abstract}

Key words: chemical desiccation, herbicide, seed size.

\section{INTRODUÇÃO}

A utilização de dessecantes em précolheita para a produção de sementes, quando realizada por ocasião da maturidade fisiológica, não prejudica a germinação e pode, em alguns casos, até melhorá-la (Domingos et al., 1997, 2000). Entretanto, trabalhos indicam efeitos negativos da adoção dessa prática sobre a qualidade de sementes (Moyer et al., 1996; Gubbels et al., 1997). Cathey \& Barry (1997), trabalhando com algodão, relataram efeito

Recebido para publicação em 13.9.2004 e na forma revisada em 17.12.2004.

Doutorando do Departamento de Fitotecnia da Universidade Federal de Viçosa - UFV, Av. P.H. Rolfs, s/n, 36570-000 ViçosaMG, <jbarbosasantos@yahoo.com.br>; ${ }^{3}$ Mestrando do Departamento de Biologia Vegetal da UFV; ${ }^{4}$ Acadêmico do curso de Agronomia da UFV; ${ }^{5}$ Professor do Departamento de Fitotecnia da UFV; ${ }^{6}$ Engenheira-Agrônoma, UFV. 
negativo acentuado sobre o vigor das sementes, exercido pela aplicação de glyphosate misturado a outros desfolhantes. Todavia, para Carvalho et al. (1978), os efeitos negativos da aplicação de dessecantes sobre a produção de sementes acontecem porque não se levam em conta os aspectos fisiológicos destas, ou seja, os produtos são aplicados antes que as sementes atinjam o ponto de maturidade fisiológica.

Pelegrini (1986) destaca aspectos a serem considerados quando se pretende usar dessecantes químicos, como: os reflexos do produto na qualidade da semente, a eventual ocorrência de resíduos tóxicos no produto colhido e a época de aplicação de tais produtos. Nesse sentido, Almeida et al. (1991) verificaram que o paraquat não deixava resíduo na semente quando aplicado com intervalo de, pelo menos, sete dias entre a aplicação e a colheita.

A utilização de dessecantes que não prejudiquem o rendimento, a germinação e o vigor da semente e permitam a antecipação da colheita consiste em prática promissora para a qualidade final da produção. O conhecimento da época da aplicação de dessecantes na cultura do feijão é de fundamental importância para a obtenção de máximo rendimento de sementes viáveis. Para fazer a dessecação, vários produtos vêm sendo recomendados (Rodrigues \& Almeida, 1998) para as diferentes culturas. Essa dessecação tem por objetivos antecipação e planejamento da colheita, funcionamento eficiente das colheitadeiras, redução na interferência das plantas daninhas na colheita e garantia de alta qualidade no produto colhido.

Uma das novas moléculas com potencial para dessecação é o carfentrazone-ethyl. Este herbicida tem-se mostrado eficiente no controle de diversas espécies de plantas daninhas tolerantes ao glyphosate, como a trapoeraba (Commelina spp.) (Correa \& Borges, 2000; Ronchi et al., 2001). O carfentrazone-ethyl pertence ao grupo químico das aril-triazolinonas e tem como mecanismo de ação a inibição da protoporfirinogênio oxidase (PPO ou PROTOX), enzima esta envolvida na rota biossintética da clorofila (HRAC, 2001). Nas plantas sensíveis tratadas com o carfentrazone-ethyl ocorre acúmulo de protoporfirinogênio IX, que, na presença da luz, catalisa a formação do oxigênio singleto, responsável pela peroxidação das membranas. Com isso, tem-se rápida dessecação das plantas tratadas, sendo os sintomas observáveis no mesmo dia da aplicação (Burga \& Corrêa, 2000).

O objetivo deste trabalho foi avaliar a qualidade de sementes de feijão colhidas após dessecação química com carfentrazone-ethyl.

\section{MATERIAL E MÉTODOS}

O experimento foi realizado em campo de produção de feijão com o cultivar Talismã, pertencente ao grupo Carioca, no período de janeiro a abril de 2004.

Foram avaliadas cinco doses do herbicida carfentrazone-ethyl $\left(0,10,30,60\right.$ e $\left.120 \mathrm{~g} \mathrm{ha}^{-1}\right)$ associadas a três épocas de aplicação $(25,30$ e 35 dias após o florescimento). A primeira aplicação correspondeu ao estádio em que 20\% das plantas de feijão apresentavam início de descoloração das primeiras vagens - final da etapa R8, segundo Fernández et al. (1985).

O delineamento experimental utilizado foi o de blocos ao acaso, no arranjo fatorial com quatro repetições. A aplicação do carfentrazone-ethyl foi feita utilizando-se um pulverizador costal de precisão, aplicando-se o equivalente a $200 \mathrm{~L} \mathrm{ha}^{-1}$ de calda. Depois de cada aplicação, avaliou-se o teor de umidade nas sementes em intervalos de dois dias. Para isso, fez-se a coleta e debulha de vagens em cada parcela nos referidos intervalos, as quais, após pesagem, foram secas em estufa a $72 \pm 1{ }^{\circ} \mathrm{C}$. Ao final de oito dias após cada aplicação, as sementes, após serem beneficiadas e secas "ao sol", foram corrigidas para 13\% de umidade pela fórmula $\mathrm{PC}=\operatorname{Pob}(100-\mathrm{U}) /$ $100-13$, em que: $\mathrm{PC}=$ peso corrigido para $13 \%$ de umidade; Pob = peso observado; e U = umidade da amostra original, determinada pelo método da estufa com circulação forçada de ar a $105^{\circ} \mathrm{C}$ por 24 horas. Em seguida, procedeu-se às seguintes avaliações:

- Peso de 100 sementes - de cada parcela foram retiradas 100 sementes, para verificação do peso após padronização para 13\% de umidade.

- Tamanho da semente - as sementes foram classificadas em peneira de crivo oblongo, sendo "menores" as que passaram pela peneira de largura 14/64" (peneira 14) e 
ficaram retidas em peneira de largura 12/ 64" (peneira 12); "médias", as que passaram pela peneira de largura 16/64" (peneira 16) e ficaram retidas na peneira 14; e "maiores", as que ficaram retidas na peneira 16.

- Teste de germinação (TG) - realizado por meio do enrolamento de duas subamostras de 50 sementes, para cada repetição de campo, em papel para germinação umedecido com água destilada na proporção de 2,5 vezes o peso do papel, que foram levados para germinador previamente regulado a $25 \pm 1{ }^{\circ} \mathrm{C}$; a avaliação foi feita aos cinco (primeira contagem) e nove (contagem final) dias após início do teste, por meio da contagem das plântulas consideradas normais segundo os critérios estabelecidos nas Regras para Análise de sementes (Brasil, 1992).

Os dados obtidos foram submetidos à análise de variância pelo teste $\mathrm{F}$, e as médias foram comparadas pelo teste de Tukey a $5 \%$ de probabilidade. Também foram ajustadas curvas de regressão para a evolução da perda de umidade das sementes.

\section{RESULTADOS E DISCUSSÃO}

Na dessecação realizada aos 25 dias após florescimento (DAF), observou-se efeito das doses do dessecante sobre a umidade das sementes somente a partir de cinco dias após a aplicação (DAA). Aos 25 DAF as sementes se encontravam com $64 \%$ de umidade, chegando, aos 8 dias após aplicação (DAA) do dessecante, a valores correspondentes a 50, 46, 42, 41 e $38 \%$, respectivamente para as doses de 0,10 , 30, 60 e $120 \mathrm{~g} \mathrm{ha}^{-1}$ (Figura 1 e Tabela 1).

A perda de umidade das sementes nas plantas dessecadas aos $30 \mathrm{DAF}$ foi maior para a dose de $120 \mathrm{~g} \mathrm{ha}^{-1}$, acentuando-se a partir de 2 DAA de forma exponencial decrescente, atingindo valores da ordem de 24 e $18 \%$, respectivamente, aos 5 e 8 DAA (Figura 1 e Tabela 1). Na ausência do dessecante, observou-se perda média de $2 \%$ de umidade por dia desde a aplicação até a colheita aos 8 DAA (Figura 1 e Tabela 1). Nas doses entre 10 e $30 \mathrm{~g} \mathrm{ha}^{-1}$, a perda de umidade foi semelhante ao longo dos 8 DAA, sendo observados, em média, $35 \%$ de umidade no momento da colheita (Figura 1 e Tabela 1).

$\mathrm{Na}$ dessecação realizada aos 35 DAF, observou-se pequena diferença entre a nãodessecação e a aplicação, mesmo na menor dose $\left(10 \mathrm{~g} \mathrm{ha}^{-1}\right)$, de carfentrazone-ethyl. Nas plantas não-dessecadas (testemunha) a perda de umidade foi mínima até 4 DAA. Todavia, a partir desta data verificou-se decréscimo de até $9 \%$ ao dia (entre 4 e 6 DAA). Nos tratamentos dessecados com 10, 30 e $60 \mathrm{~g} \mathrm{ha}^{-1} \mathrm{de}$ carfentrazone-ethyl, a redução média de umidade foi de $5 \%$ ao dia até 5 DAA e de $2 \%$ entre 5 e 8 DAA, conforme equações ajustadas (Figura 1 e Tabela 1). Na maior dose do dessecante aplicada (120 $\left.\mathrm{g} \mathrm{ha}^{-1}\right)$, constatou-se queda de $7 \%$ de umidade por dia até os 3 DAA e de $1 \%$ de umidade por dia do terceiro ao oitavo DAA (Figura 1 e Tabela 1).

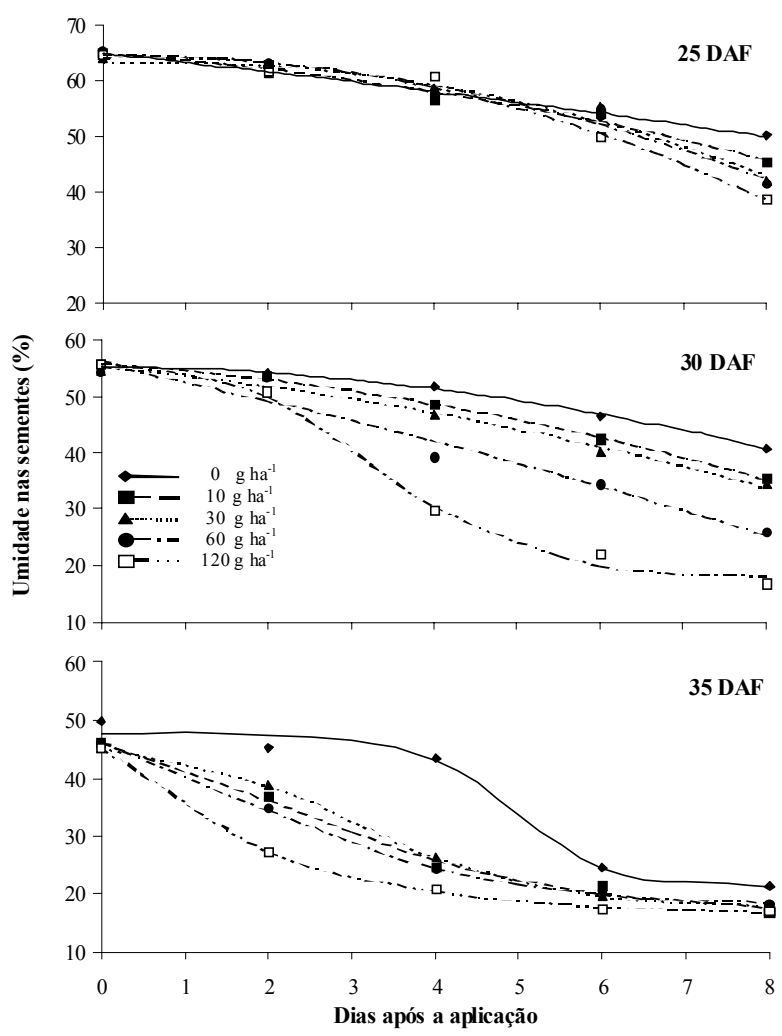

Figura 1 - Evolução da perda de umidade (\%) nas sementes de feijão (cultivar Talismã) após dessecação com carfentrazone-ethyl, em diferentes doses aplicadas aos 25 , 30 e 35 dias após o florescimento (DAF).

Planta Daninha, Viçosa-MG, v. 22, n. 4, p. 633-639, 2004 
Tabela 1 - Equações de regressão correlacionando o grau de umidade de sementes de feijão (cultivar Talismã) e dias após a aplicação (D), em três épocas distintas (25 30 e 35 dias após o florescimento - DAF), do carfentrazone-ethyl em diferentes doses $\left(\mathrm{g} \mathrm{ha}^{-1}\right)$ como dessecante

\begin{tabular}{|c|c|c|}
\hline Dose aplicada $\left(\mathrm{g} \mathrm{ha}^{-1}\right)$ & Equação ajustada $^{1 /}$ & $\mathrm{R}^{2}$ \\
\hline \multicolumn{3}{|c|}{$25 \mathrm{DAF}$} \\
\hline 0,0 & $\hat{\mathrm{Y}}=-0,0403 \mathrm{D}^{2}-1,5502 \mathrm{D}+64,885$ & 0,99 \\
\hline 10,0 & $\hat{\mathrm{Y}}=-0,1644 \mathrm{D}^{2}-1,0838 \mathrm{D}+65,081$ & 0,98 \\
\hline 30,0 & $\hat{\mathrm{Y}}=-0,3846 \mathrm{D}^{2}+0,5558 \mathrm{D}+63,247$ & 0,96 \\
\hline 60,0 & $\hat{Y}=-0,3533 D^{2}+0,0185 D+64,819$ & 0,97 \\
\hline 120,0 & $\hat{\mathrm{Y}}=-0,4683 \mathrm{D}^{2}+0,5532 \mathrm{D}+64,156$ & 0,98 \\
\hline \multicolumn{3}{|c|}{$30 \mathrm{DAF}$} \\
\hline 0,0 & $\hat{Y}=-0,2052 D^{2}-0,1907 D+55,335$ & 0,99 \\
\hline 10,0 & $\hat{\mathrm{Y}}=-0,1945 \mathrm{D}^{2}-1,0085 \mathrm{D}+55,843$ & 0,98 \\
\hline 30,0 & $\hat{\mathrm{Y}}=-0,1614 \mathrm{D}^{2}-1,3750 \mathrm{D}+55,221$ & 0,98 \\
\hline 60,0 & $\hat{\mathrm{Y}}=-0,1052 \mathrm{D}^{2}+2,9267 \mathrm{D}+55,557$ & 0,96 \\
\hline 120,0 & $\hat{\mathrm{Y}}=18,1409+38,8724 /(1+\exp (-(\mathrm{D}-3,3343) /-0,8846))$ & 0,97 \\
\hline \multicolumn{3}{|c|}{$35 \mathrm{DAF}$} \\
\hline 0,0 & $\hat{Y}=21,0521+26,6012 /(1+\exp (-(D-4,9033) /-0,5785))$ & 0,95 \\
\hline 10,0 & $\hat{\mathrm{Y}}=16,7254+37,4797 /(1+\exp (-(\mathrm{D}-2,1412) /-1,6354))$ & 0,97 \\
\hline 30,0 & $\hat{Y}=17,6607+29,6915 /(1+\exp (-(D-3,0044) /-1,1403))$ & 0,99 \\
\hline 60,0 & $\hat{Y}=18,2192+36,8985 /(1+\exp (-(\mathrm{D}-1,6633) /-1,4609))$ & 0,99 \\
\hline 120,0 & $\hat{\mathrm{Y}}=16,3027+687,1522 /(1+\exp (-(\mathrm{D}-6,3094) /-2,0204))$ & 0,99 \\
\hline
\end{tabular}

1/ Significativo a $1 \%$ de probabilidade pelo teste $\mathrm{t}$.

Admitindo-se que na ausência de dessecantes o melhor momento observado para a colheita ocorreu no período entre 42 e $43 \mathrm{DAF}$, pode-se inferir que a utilização do carfentrazone como dessecante pode antecipar a colheita do feijão em até sete dias nas menores doses ( 10 e $30 \mathrm{~g} \mathrm{ha}^{-1}$ ), com base na umidade alcançada nas sementes (em torno de 35\%) na colheita (dessecação aos $30 \mathrm{DAF}$ ). Resultados semelhantes foram obtidos por Marchiori Jr. et al. (2002), os quais observaram que a dessecação com carfentrazone-ethyl (30 $\left.\mathrm{g} \mathrm{ha}^{-1}\right)$ para produção de sementes de canola antecipou a colheita sete dias sem interferência na produtividade e qualidade fisiológica destas.

O peso de 100 sementes foi influenciado pela época de dessecação e pela dose do dessecante (Tabela 2). Resultados semelhantes foram observados por Forbes \& Pratley (1983), Moyer et al. (1996) e Gubbels et al. (1997), respectivamente para sementes de feijão, alfafa e soja. Entretanto, Domingos et al. (2000), em dessecação realizada com o paraquat ou com a mistura paraquat + diquat sobre o feijoeiro, verificaram que o peso de sementes não foi afetado.

Planta Daninha, Viçosa-MG, v. 22, n. 4, p. 633-639, 2004
Nas sementes colhidas ao final da primeira época de dessecação (25 DAF), observou-se redução do peso com o aumento da dose do dessecante. Enquanto na ausência do produto 100 sementes pesaram, em média, 19,31 g, nas maiores doses esse valor foi reduzido para 17,76 e $15,01 \mathrm{~g}$, respectivamente para as doses de 60 e $120 \mathrm{~g} \mathrm{ha}^{-1}$ de carfentrazone-ethyl (Tabela 2). Nas menores doses aplicadas (10 e $30 \mathrm{~g} \mathrm{ha}^{-1}$ ), verificou-se apenas tendência na redução do peso de 100 sementes, porém sem diferirem da testemunha. O menor peso de 100 sementes observado em plantas dessecadas com elevadas doses do dessecante pode ser atribuído à rápida perda de umidade das sementes resultantes da ação do dessecante. Possivelmente a perda acelerada de água prejudicou o desvio de fotoassimilados para as sementes, proporcionando desigualdade no enchimento destas, principalmente na primeira época de aplicação, quando o teor de água era superior a $60 \%$ do peso total da semente. Essa hipótese é reforçada quando se observa que, para as plantas dessecadas aos 30 e 35 DAF, não se observou diferença no valor médio do peso de 100 sementes mesmo entre as diferentes doses do dessecante (Tabela 2). 
Tabela 2 - Peso de 100 sementes de feijão, cultivar Talismã, sob efeito de diferentes doses de carfentrazone-ethyl aplicado como dessecante aos 25, 30 e 35 dias após o florescimento (DAF)

\begin{tabular}{|c|c|c|c|c|}
\hline \multirow{2}{*}{$\begin{array}{c}\text { Dose } \\
\left(\mathrm{g} \mathrm{ha}^{-1}\right)\end{array}$} & \multicolumn{4}{|c|}{ Peso de 100 sementes $(\mathrm{g})$} \\
\hline & $25 \mathrm{DAF}$ & $30 \mathrm{DAF}$ & $35 \mathrm{DAF}$ & Média \\
\hline 0,0 & 19,31 a $A$ & 19,79 a A & 19,31 a $\mathrm{A}$ & 19,47 \\
\hline 10,0 & $19,18 \mathrm{ab} \mathrm{A}$ & 19,07 a A & 19,69 a A & 19,31 \\
\hline 30,0 & $18,82 \mathrm{abB}$ & $19,19 \mathrm{a} \mathrm{AB}$ & 20,42 a $\mathrm{A}$ & 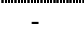 \\
\hline 60,0 & $17,76 \mathrm{~b} \mathrm{~B}$ & 20,14 a A & 19,76 a A & - \\
\hline 120,0 & $15,01 \mathrm{c} \mathrm{B}$ & 19,10 a A & 19,34 a A & $=$ \\
\hline
\end{tabular}

Médias seguidas de letras iguais, minúscula na coluna e maiúscula na linha, não diferem entre si pelo teste de Tukey a $5 \%$ de probabilidade.

Quanto ao efeito da época de dessecação no peso das sementes, foi observado que, para as doses de carfentrazone-ethyl superiores a $30 \mathrm{~g} \mathrm{ha}^{-1}$, o peso das sementes foi reduzido somente na dessecação realizada aos $25 \mathrm{DAF}$, não se constatando diferença entre as épocas para a dose de $10 \mathrm{~g} \mathrm{ha}^{-1}$ (Tabela 2).

Avaliando o efeito da dessecação sobre o tamanho das sementes produzidas, observase que, quando a aplicação foi realizada aos 25 DAF, a maior parte das sementes foi classificada como "médias" (retidas entre as peneiras de crivo 14/64" e 16/64"), com $65,46 \%$ do total (Tabela 3 ). A proporção relativa de sementes menores foi superior para as plantas dessecadas com $120 \mathrm{~g} \mathrm{ha}^{-1}$ do produto; conseqüentemente, houve redução na proporção de sementes "maiores" (retidas na peneira 16/64") para essa mesma dose, evidenciando efeito tóxico desta quando aplicada nessa época (Tabela 3).

A dessecação realizada aos 30 DAF, independentemente da dose utilizada do produto, não interferiu na proporção de tamanhos de sementes, sendo observadas as seguintes porções relativas: $6,44 \%$ para sementes "menores", 63,67\% para sementes "médias" e 29,89\% para sementes "maiores" (Tabela 3).

Na última época de dessecação (35 DAF), a proporção de sementes "médias" foi semelhante, independentemente da dose aplicada, produzindo $63,33 \%$ do total nesse tamanho. Entretanto, observou-se que, na ausência do dessecante, a proporção de sementes "menores" foi maior em detrimento das "maiores". Enquanto para todos os tratamentos que receberam o dessecante a menor proporção de sementes "maiores" foi de 29,76\% (na dose de $120 \mathrm{~g} \mathrm{ha}^{-1}$ ), a testemunha atingiu 22,07\% nessa mesma época (Tabela 3).

Na comparação realizada entre as épocas para cada tamanho de semente, não se observou diferença entre a testemunha até a dose de $30 \mathrm{~g} \mathrm{ha}^{-1}$ do dessecante; contudo, para as maiores doses (60 e $120 \mathrm{~g} \mathrm{ha}^{-1}$ ), constatouse aumento do tamanho da semente com a época de dessecação (Figura 2). Para a dose de $60 \mathrm{~g} \mathrm{ha}^{-1}$ a proporção de sementes "menores" foi maior na primeira época de dessecação $(9,73 \%$ das sementes), comparada às demais épocas (30 e $35 \mathrm{DAF}$ ), as quais apresentaram média de 5,38\%. Ao mesmo tempo, a proporção

Tabela 3 - Efeito da aplicação de carfentrazone-ethyl como dessecante do feijoeiro (cultivar Talismã) em diferentes épocas (25, 30 e 35 dias após o florescimento - DAF) sobre o tamanho das sementes (\%) classificadas em "menores", "médias" e "maiores"

\begin{tabular}{|c|c|c|c|c|c|c|c|}
\hline \multirow{2}{*}{$\begin{array}{c}\text { Época de } \\
\text { aplicação }\end{array}$} & \multirow{2}{*}{$\begin{array}{c}\text { Tamanho das } \\
\text { sementes }\end{array}$} & \multicolumn{6}{|c|}{ Dose de carfentrazone-ethyl $\left(\mathrm{g} \mathrm{ha}^{-1}\right)$} \\
\cline { 3 - 8 } & & 0,0 & 10,0 & 30,0 & 60,0 & 120,0 & Média \\
\hline \multirow{3}{*}{$25 \mathrm{DAF}$} & Menores & $6,25 \mathrm{~b}$ & $7,06 \mathrm{~b}$ & $7,26 \mathrm{~b}$ & $9,73 \mathrm{~b}$ & $16,00 \mathrm{a}$ & - \\
& Médias & $61,47 \mathrm{a}$ & $64,07 \mathrm{a}$ & $64,16 \mathrm{a}$ & $66,36 \mathrm{a}$ & $71,26 \mathrm{a}$ & 65,46 \\
& Maiores & $32,28 \mathrm{a}$ & $28,86 \mathrm{a}$ & $28,58 \mathrm{a}$ & $23,91 \mathrm{ab}$ & $12,74 \mathrm{~b}$ & - \\
\hline \multirow{3}{*}{$30 \mathrm{DAF}$} & Menores & $5,68 \mathrm{a}$ & $6,92 \mathrm{a}$ & $6,21 \mathrm{a}$ & $6,07 \mathrm{a}$ & $7,33 \mathrm{a}$ & 6,44 \\
& Médias & $61,99 \mathrm{a}$ & $64,90 \mathrm{a}$ & $63,25 \mathrm{a}$ & $64,35 \mathrm{a}$ & $63,84 \mathrm{a}$ & 63,67 \\
\hline & Maiores & $32,32 \mathrm{a}$ & $28,17 \mathrm{a}$ & $30,54 \mathrm{a}$ & $29,58 \mathrm{a}$ & $28,83 \mathrm{a}$ & 29,89 \\
\hline \multirow{3}{*}{$35 \mathrm{DAF}$} & Menores & $8,81 \mathrm{a}$ & $4,19 \mathrm{~b}$ & $5,40 \mathrm{ab}$ & $4,70 \mathrm{~b}$ & $5,84 \mathrm{ab}$ & - \\
& Médias & $69,12 \mathrm{a}$ & $59,14 \mathrm{a}$ & $61,96 \mathrm{a}$ & $62,05 \mathrm{a}$ & $64,40 \mathrm{a}$ & 63,33 \\
\hline & Maiores & $22,07 \mathrm{~b}$ & $36,67 \mathrm{a}$ & $32,64 \mathrm{ab}$ & $33,25 \mathrm{ab}$ & $29,76 \mathrm{ab}$ & - \\
\hline
\end{tabular}

Médias seguidas de letras iguais na linha, para cada tamanho de semente, não diferem entre si pelo teste de Tukey a $5 \%$ de probabilidade. 
de sementes "maiores" foi superior para a dessecação realizada aos 30 e 35 DAF (Figura 2). Para a dose de $120 \mathrm{~g} \mathrm{ha}^{-1}$, o comportamento entre as épocas de dessecação foi semelhante ao apresentado para a dose de $60 \mathrm{~g} \mathrm{ha}^{-1}$, sendo as médias da proporção de sementes $16 \mathrm{e}$ $12,74 \%$, respectivamente, "menores" e "maiores" para dessecação realizada aos $25 \mathrm{DAF}$, contra 6,58 e 29,29\%, respectivamente "menores" e "maiores", para dessecação realizada aos 30 e 35 DAF (Figura 2).

Não se observou efeito da dessecação ou época de aplicação sobre a germinação das sementes; aos cinco dias após serem levadas ao germinador (primeira contagem), para o teste de vigor, os tratamentos apresentaram, em média, 99\% de plântulas normais.

Efeitos de dessecantes não afetando a germinação de sementes de feijão foram obtidos também por Domingos et al. (2000), trabalhando com cultivares do grupo carioca. No entanto, variações na germinação de sementes mediante emprego de dessecantes têm sido comuns para a cultura da soja (Pereira et al., 1976; Carvalho et al., 1978; Batista \& Barros, 1980). Os efeitos negativos da utilização de dessecantes podem ser maiores depois de determinado tempo de armazenamento das sementes, quando estas têm o vigor diminuído. Neste experimento, as sementes não foram armazenadas, sendo todas as avaliações realizadas logo após a colheita.

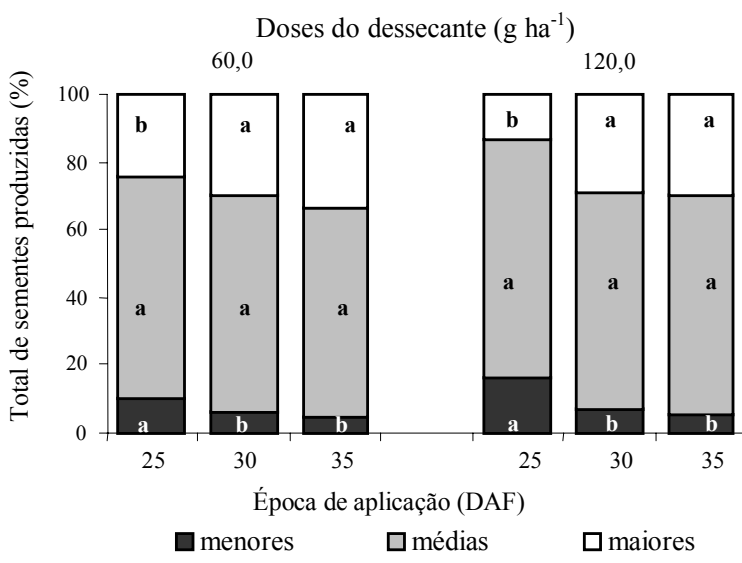

Figura 2 - Efeito da aplicação de carfentrazone-ethyl como dessecante do feijoeiro (cultivar Talismã) aos 25, 30 e 35 DAF sobre o tamanho das sementes (\%) classificadas em "menores", "médias" e "maiores". Médias seguidas de letras iguais para cada dose, dentro de um mesmo tamanho, não diferem entre si pelo teste de Tukey a $5 \%$ de probabilidade.
Fazendo uma análise integrada dos resultados, conclui-se que a utilização de carfentrazone-ethyl como dessecante na cultura do feijoeiro, visando produção de sementes, é viável, desde que se utilizem doses entre 10 e $30 \mathrm{~g} \mathrm{ha}^{-1}$, aos 30 dias após o florescimento, quando as sementes já atingiram a maturidade fisiológica, caracterizada pelo início da mudança na cor dos grãos, ou final da etapa R8, etapa esta em que foram obtidos os melhores resultados.

\section{LITERATURA CITADA}

ALMEIDA F. S.; PINEDA-AGUILAR, A.; RODRIGUES, B. N. Resíduos de paraquat em grãos de soja quando usado como dessecante da cultura. Planta Daninha, v. 9, n. 2, p. 85-91, 1991.

BATISTA, O. C.; BARROS, A. C. S. A. Efeitos de dessecantes na natureza e na qualidade de sementes de soja (Glycine $\max$ L. Merril). Tecnologia de Sementes, v. 3, n. 2, p. 19-25, 1980.

BRASIL. Ministério da Agricultura e Reforma Agrária. Regras para análise de sementes. Brasília: SNDA/ DNDV/CLAV, 1992. $365 \mathrm{p}$.

BURGA, C. A.; CORRÊA, L. E. A. Carfentrazone no controle de folhas largas, em aplicação em pós-emergência na cultura do milho. In: CONGRESSO BRASILEIRO DA CIÊNCIA DAS PLANTAS DANINHAS, 22., 2000, Foz do Iguaçu. Resumos... Londrina: SBCPD, 2000. p. 272.

CARVALHO, N. M.; DURIGAN, J. F.; BARRETO, M. Aplicação pré-colheita de dessecantes de soja (Glycine max (L.) Merrill) da cultivar "Viçoja". II. Efeitos imediatos sobre a germinação de sementes. Científica, v. 6, p. 209-213, 1978.

CATHEY, G. W.; BERRY, H. R. Evaluation of glyphosate as a harvest-aid chemical on cotton. Agronomy Journal, v. 69, p. 11-14, 1997.

CORRÊA, L. E. A.; BORGES, A. Glyphosate + carfentrazone-ethyl: controle de ervas problemas. In: CONGRESSO BRASILEIRO DA CIÊNCIA DAS PLANTAS DANINHAS, 22., 2000, Foz do Iguaçu. Resumos... Londrina: SBCPD, 2000. p. 463.

DOMINGOS, M.; SILVA, A. A.; SILVA, J. F. Qualidade de sementes de feijão afetada por dessecantes, em quatro estádios de aplicação. Revista Brasileira de Sementes, v. 19 , p. 276-283, 1997.

DOMINGOS, M.; SILVA, A. A.; SILVA, J. F. Qualidade da semente de feijão armazenada após dessecação química das plantas, em quatro estádios de aplicação. Acta Scientiarum, v. 22, p. 1143-1148, 2000. 
FERNÁNDEZ, F.; GEPTS, P.; LÓPEZ, M. Etapas de desarrollo em la planta de frijol. In: LÓPEZ, M.; FERNÁNDEZ, F.; SCHOONHOVEN, A. (Eds.) Frijol: investigación y producción. Cali: PNUD, CIAT, 1985. p. 61-78.

FORBES, J. L.; PRATLEY, J. E. The use of desiccant, defoliant and growth regulating sprays to advance the harvest of edible dry beans (Phaseolus vulgaris) in Tasmania. Aust. J. Exp. Agric. Animal Husband, v. 23, p. 426-428, 1983.

GUBBELS, H.; BONNER, M; KENASCHUC, E. O. Use of desiccant to reduce frost damage in immature flax.

Canadian J. Plant Sci., v. 74, p. 121-123, 1997.

HERBICIDE-RESISTENCE-ACTION-COMMITEE -

HRAC. Classification of herbicides according to mode of action. Disponível em: $<\mathrm{http}$ //www.plantprotection.org/ hrac/moa2001.htm>. Acesso em: 29 jan. 2001.

MARCHIORI, JR., O. et al. Qualidade e produtividade de sementes de canola (Brassica napus) após aplicação de dessecantes em pré-colheita. Planta Daninha, v. 20, n. 2, p. $253-262,2002$.
MOYER, J. R. et al. Desiccant of alfafa for seed production with diquat and glufosinate. Canadian J. Plant Sci., v. 76, p. 435-439, 1996.

PELEGRINI, H. F. Maturação das sementes e dessecação química do feijoeiro em cultivo de inverno. 1986. 81 f. Dissertação (Mestrado em Tecnologia de Sementes) - Universidade Federal de Pelotas, Pelotas, 1986.

PEREIRA, J.L.; HONDA, A. I.; SARTORI, S. Efeito da dessecação pré-colheita nos grãos de soja. In: SEMINÁRIO BRASILEIRO DE HERBICIDAS E ERVAS DANINHAS, 11., 1976, Londrina. Resumos... Londrina: 1976. p. 116117.

RODRIGUES, B. N.; ALMEIDA, F. S. (Ed.) Guia de herbicidas. 4.ed. Londrina: 1998. 648 p.

RONCHI, C. P.; SILVA, A. A.; FERREIRA, L. R. Manejo de plantas daninhas na cultura do café. Viçosa: Suprema Gráfica e Editora, 2001. 94 p. 